\title{
PENGARUH ORIENTASI ETIKA, PENGALAMAN DAN KOMPETENSI AUDITOR INTERNAL TERHADAP SKEPTISISME PROFESIONAL SERTA DAMPAKNYA TERHADAP KUALITAS HASIL AUDIT \\ (Survey Pada Inspektorat Jenderal Kementerian Agama RI)
}

\author{
Darwanto $^{1}$, Yani Kurniasih ${ }^{2}$ \\ ${ }^{1}$ Inspektorat Jenderal Kementerian Agama, ${ }^{2}$ STIE DR. KHEZ Muttaqien Purwakarta \\ ${ }^{1}$ wanto.aki@gmail.com, ${ }^{2}$ yanikurniasih1@gmail.com
}

\begin{abstract}
The aims of this research to prove and explain the positive influence of ethical orientation, experience and competence on the quality of the audit results either directly or through professional skepticism. Methods of analysis using path analysis with significance level of 0.05 (5\%). The population in this research is the auditor who acts as team members in audits at the Inspectorate General of the Ministry of Religious Affairs. The sample used were 103 respondents using cluster random sampling method to the audit teams. The test results on the analysis of the level of substructure 1 revealed that ethical orientation and experience have no positive influence to professional skepticism, while competence has positive influence to professional skepticism. The test results on the analysis of the level of the substructure 2 revealed that ethical orientation, experience, and competence have no positive influence to the quality of the audit results, while professional skepticism has positive influence the quality of the audit results. The test results on the analysis of indirect influence revealed that the ethical orientation and experience have no positive influence to the quality of the audit results through professional skepticism, while competence has positive influence to the quality of the audit results through professional skepticism.
\end{abstract}

Keywords : ethical orientation, experience, competence, professional skepticism, the quality of the audit results.

\section{PENDAHULUAN}

\begin{abstract}
Penguatan
pemerintahan dilakukan untuk menjamin pengelolaan keuangan negara dan pelaksanaan program agar dapat sesuai dengan rencana yang telah ditetapkan dan mencegah terjadinya penyimpangan. Pentingnya fungsi audit internal untuk meningkatkan akuntabilitas dan transparansi yang lebih baik dalam sektor publik (Belay, 2007: 8), sehingga tuntutan terhadap hasil audit yang berkualitas semakin tinggi untuk mengevaluasi dan
\end{abstract}

meningkatkan kinerja organisasi secara keseluruhan. Laporan hasil audit yang berkualitas tersebut harus memenuhi kriteria yaitu: tepat waktu, lengkap, akurat, obyektif, meyakinkan, serta jelas, dan seringkas mungkin (Permenpan Nomor: PER/05/M.PAN/03/2008), oleh karena itu, perhatian secara terus menerus terhadap temuan audit beserta rekomendasinya dapat membantu auditor untuk menjamin terwujudnya manfaat audit yang dilakukan dan 
mampu memberikan hasil audit yang berkualitas. Kualitas hasil audit merupakan refleksi dari implementasi proses audit.

Beberapa peneliti telah menguji faktor-faktor yang dapat mempengaruhi kualitas hasil audit (Sukriah dkk, 2010; Januarti dan Faisal, 2010; Queena dan Rohman, 2014). Kualitas pengendalian internal secara langsung dapat dipengaruhi oleh kualitas dari personalia (Dauber, 2008: 95), dalam hal ini dapat berupa skeptisisme profesional, orientasi etika, pengalaman, dan kompetensi yang dimiliki oleh auditor. Para teoritisi dan praktisi auditing sepakat bahwa skeptisisme profesional merupakan sikap mutlak yang harus dimiliki auditor (Tuanakotta, 2011: 71). Skeptisisme profesional juga dipengaruhi oleh beberapa faktor seperti etika, pengalaman, dan kompetensi (Suraida, 2005; Kee dan Knox, 1970:
Shaub dan Lawrence, 1996). Dalam beberapa penelitian audit eksternal, hasil audit diproksikan dalam judgement auditor ataupun ketepatan pemberian opini. Skeptisisme dapat menjadi intervening antara etika, pengalaman, dan kompetensi terhadap ketepatan pemberian opini (Pratiwi dan Januarti, 2013; Sabrina K. dan Januarti, 2012; Suraida, 2005).

Regulator dan peneliti akademis telah menunjukkan bahwa skeptisisme profesional berkaitan erat dengan deteksi kecurangan (Hurtt, 2010: 150), sehingga pentingnya penelitian ini dapat dilihat dari masih banyaknya kecurangan dalam pengelolaan keuangan negara yang dapat ditunjukkan dengan penanganan tindak pidana korupsi pada instansi pemerintahan oleh Komisi Pemberantasan Korupsi (KPK) yang dijelaskan dalam tabel sebagai berikut:

Tabel 1

Tabulasi Data Penanganan Korupsi Berdasarkan Instansi Tahun 2004-2018 (per 24 Agustus 2018)

\begin{tabular}{llccccccc}
\hline \multirow{2}{*}{ No. } & \multirow{2}{*}{ Instansi } & \multicolumn{7}{c}{ Tahun } \\
\cline { 3 - 8 } & $\begin{array}{r}2004- \\
2013\end{array}$ & 2014 & 2015 & 2016 & 2017 & 2018 & \multirow{2}{*}{ Jumlah } \\
\hline \hline 1. & DPR dan DPRD & 34 & 2 & 3 & 15 & 9 & 2 & 65 \\
\hline 2. & Kementerian/Lembaga & 157 & 26 & 21 & 39 & 31 & 13 & 287 \\
\hline 3. & BUMN/BUMD & 22 & 0 & 5 & 11 & 13 & 0 & 51 \\
\hline 4. & Komisi & 20 & 0 & 0 & 0 & 0 & 0 & 20 \\
\hline 5. & Pemerintah Provinsi & 42 & 11 & 18 & 13 & 15 & 17 & 116 \\
\hline 6. & Pemkab/Pemkot & 78 & 19 & 10 & 21 & 53 & 53 & 234 \\
\hline & Jumlah & $\mathbf{3 5 3}$ & $\mathbf{5 8}$ & $\mathbf{5 7}$ & $\mathbf{9 9}$ & $\mathbf{1 2 1}$ & $\mathbf{8 5}$ & $\mathbf{7 7 3}$ \\
\hline
\end{tabular}

Sumber : KPK RI (2018) melalui https://acch.kpk.go.id/id/statistik/tindak-pidanakorupsi/tpk-berdasarkan-instansi, diakses tanggal 24 Agustus 2018 (data diolah)

Tabel 1 menunjukkan bahwa penanganan tindak pidana korupsi lebih banyak ditemukan di lingkungan Kementerian/Lembaga (K/L) sebanyak 287 perkara. Terbongkarnya kasus kecurangan (fraud) di masyarakat, menjadikan auditor sebagai sorotan termasuk auditor internal pemerintah yang merupakan penjamin mutu dari pelaksanaan pengawasan intern pemerintah.

$\mathrm{K} / \mathrm{L}$ yang memiliki semakin banyak satuan kerja, membutuhkan jumlah dan kapabilitas auditor yang juga tinggi. Dari sisi jumlah, banyaknya auditor harus sebanding dengan jumlah kebutuhan satuan kerja yang perlu diaudit. Lebih lanjut, dalam beban kerja 
dan kompleksitas permasalahan yang tinggi, auditor yang memiliki kapabilitas memadai, baik dari sisi pengalaman, kompetensi, dan juga orientasi etika dapat mengimplementasikan proses audit dengan baik sehingga dapat mendeteksi berbagai kecurangan dengan sikap skeptisisme profesional yang dimiliki dan berimplikasi pada hasil audit yang berkualitas, dalam hal ini Kemeneterian Berdasarkan latar belakang di atas, dapat dikemukakan identifikasi masalah sbb:

1. Seberapa besar pengaruh orientasi etika, pengalaman, dan kompetensi terhadap skeptisisme profesional auditor.

2. Seberapa besar pengaruh orientasi etika, pengalaman, kompetensi, dan

Tujuan dari penelitian ini adalah:

1. Untuk mengetahui signifikasi dan besarnya pengaruh positif orientasi etika, pengalaman, dan kompetensi terhadap skeptisisme profesional auditor baik secara parsial maupun simultan di Inspektorat Jenderal Kementerian Agama.

2. Untuk mengetahui signifikasi dan besarnya pengaruh positif orientasi etika, pengalaman, kompetensi, dan

Penelitian ini dibatasi pada aspek-aspek berikut:

1. Unit analisis dalam penelitian ini adalah auditor yang diperankan sebagai anggota tim dalam penugasan audit.

2. Orientasi etika, pengalaman, kompetensi, dan skeptisisme profesional diukur menggunakan kuesioner yang diberikan kepada

\section{TINJAUAN PUSTAKA}

\section{Kualitas Hasil Audit}

Secara konseptual, kita dapat melihat kualitas audit dalam tiga aspek mendasar: input (inputs), output (outputs), dan faktor-faktor konteks (context factors) (IAASB, 2011: 4). Beberapa peneliti telah melakukan review terkait penelitian tentang
Agama memiliki satuan kerja terbanyak dibandingkan dengan $\mathrm{K} / \mathrm{L}$ yang lain (BPK RI, 2017). Berdasarkan latar belakang dan fenomena yang telah dipaparkan di atas, maka dapat diduga bahwa orientasi etika, pengalaman, dan kompetensi auditor internal memiliki pengaruh terhadap skeptisisme profesional dan berimplikasi terhadap kualitas hasil audit. skeptisisme profesional auditor terhadap kualitas hasil audit.

3. Seberapa besar pengaruh orientasi etika, pengalaman, dan kompetensi terhadap kualitas hasil audit melalui skeptisisme profesional auditor.

skeptisisme profesional auditor terhadap kualitas hasil audit baik secara parsial maupun simultan di Inspektorat Jenderal Kementerian Agama.

3. Untuk mengetahui signifikasi dan besarnya pengaruh positif orientasi etika, pengalaman, dan kompetensi terhadap kualitas hasil audit melalui skeptisisme profesional auditor.

auditor yang diperankan sebagai anggota tim, sedangkan kualitas hasil audit diukur menggunakan kuesioner yang diberikan kepada auditor yang diperankan sebagai ketua tim untuk menilai anggota tim. kualitas audit seperti: Bing dkk (2014); Bedard dkk (2010); Chadegani (2011); DeFond dan Zhang (2014); Francis (2011); Martin (2013); Qi dkk (2015); Wooten (2003); dan Knechel dkk (2013). Kualitas audit dalam konteks audit internal seringkali diproksikan ke 
dalam efektivitas fungsi audit internal (Ziegenfuss, 2000; Mihret dan Yismaw, 2007; Arena dan Azzone, 2007; Enofe dkk, 2013; Abbott dkk, 2016).

Kualitas audit internal ditunjukkan oleh kemampuan untuk menyediakan temuan dan rekomendasi audit yang berguna, hal ini merupakan salah satu faktor yang paling menonjol yang efektivitas audit (Enofe dkk, 2013: 164; Sawyer: 1995). Kualitas audit internal

\section{Orientasi Etika}

Dilema etika menuntut auditor membuat keputusan etis. Terdapat beberapa model "ethical decision making" dalam bisnis yang sebagian besar para ahli setuju bahwa keputusan etis dipengaruhi oleh moral development atau orientasi etika (ethical orientation) para pengambil keputusan (Zarkasyi, 2009: 4). Shaub dan Lawrence (1996: 127) mendefinisikan orientasi etika sebagai berikut:

Ethical orientation is
predesposition derived from an individual's cultural environment and previous life experiences. Ethical orientation refers to the

\section{Pengalaman}

Pengalaman dalam bekerja menunjukkan pekerjaan yang pernah dilakukan seseorang serta memberikan peluang di masa mendatang untuk menyelesaikan pekerjaan dengan lebih baik dan mengurangi risiko kesalahan. Noe (2010: 364) mendefinisikan pengalaman dalam bekerja sebagai berikut: Job experiences refer to relationships, problems, demands, tasks, or other features that employees face in their jobs. Setiap hal yang dilalui berkaitan dengan pekerjaan membuat seseorang semakin mengerti seluk beluk dan teknis pekerjaan yang akan dilaluinya. jika dilihat dari sisi output, maka terkait dengan penyajian temuan dan rekomendasi audit yang terangkum dalam laporan hasil audit sebagaimana konsep output yang diajukan IAASB (2011). Laporan audit internal memiliki tujuan dasar untuk menggambarkan audit yang direncanakan dan dijadwalkan dan untuk mengkomunikasikan hasil audit itu sendiri (Moeller, 2009: 351).

view adopted by an individual when ethical issues are encountered, as opposed to the process used to solve ethical dilemmas.

Dari uraian di atas, maka orientasi etika merupakan kecondongan etika seseorang yang mempengaruhi pengambilan keputusan dalam menghadapi dilema etika. Forsyth (1980: 175) berpendapat bahwa orientasi etika adalah tujuan utama perilaku profesional yang berkaitan erat dengan moral dan nilai-nilai yang berlaku dan digerakkan oleh dua karakteristik yaitu idealisme dan relativisme.

Pengalaman dalam penelitian ini menggunakan konsep dari Noe (2010), mengacu pada hubungan, masalah, tuntutan, tugas, atau fitur lainnya yang dihadapi karyawan dalam pekerjaan, dengan dimensi job experiences yang teridiri dari dua indikator yaitu: lama bekerja dalam tahun (years an auditor) dan level dari pengalaman (experience level), dapat dilihat dari penugasan. Years an auditor diadopsi dari penelitian Herda dan Martin (2016: 10) dan Ye dkk (2014), sedangkan experience level diadopsi dari penelitian Libby dan Frederick (1990) dan Arens dkk (2014: 29). 


\section{Kompetensi}

Definisi kompetensi menurut Shermon (2004: 11) yaitu: $A$ competency is an underlying characteristic of a person, which enables him deliver superior performance in given a job. The Institute of Internal Auditors (The IIA) $(2013,2)$ mendefinisikan kompetensi sebagai berikut: A competency is the ability of an individual to perform a job or task properly, being a set of defined knowledge, skills and behavior. Lebih lanjut, seorang auditor mutu internal dituntut memiliki kompetensi (pengetahuan, kemampuan, dan sikap) yang dapat menjamin proses audit mutu internal berjalan efektif (Soesilo, 2003: 215). Kompetensi adalah kemampuan dan karakteristik yang dimiliki oleh seorang Pegawai Negeri Sipil berupa pengetahuan, keahlian, dan sikap perilaku yang diperlukan dalam pelaksanaan tugasnya (BPKP, 2010). HM Treasury (2007: 5) menjelaskan mengenai definisi kompetensi sebagai berikut: Clusters of behaviours, skills and knowledge which are needed to undertake a job effectively.

Dari berbagai definisi yang dijelaskan diatas, maka dapat ditarik kesimpulan bahwa kompentensi bagi auditor dengan pendekatan reflektif meliputi unsur perilaku (behaviour) dan unsur output pekerjaan (job outputs), di dalamnya mencakup karakteristik yang terdiri dari pengetahuan (knowledge), keahlian (skill), dan sikap (attitude), sedangkan indikator dengan pendekatan formatif dapat meliputi sertifikasi yang dimiliki, pengalaman, dan pelatihanpelatihan yang diikuti (Dauber, 2008; Suraida,

\section{KERANGKA PEMIKIRAN DAN PENGEMBANGAN HIPOTESIS}

Dalam suatu organisasi ada banyak pihak yang berkepentingan. Dalam konteks pelaksanaan audit, benturan kepentingan mungkin terjadi. Saat auditor ingin mengungkapkan informasi, namun auditi bisa saja tidak ingin informasi tersebut dilaporkan (dipublikasikan) dikarenakan berbagai hal seperti terdapat unsur fraud, ketidakpatuhan, dan penurunan kinerja. Atas peristiwa tersebut maka terdapat konflik didalamnya yang menjadi sebuah dilema etika bagi auditor untuk membuat keputusan terkait dengan imbalan ekonomis yang mungkin terjadi di sisi lainnya. Dari sisi auditor, situasi dilema etika tersebut dapat dijelaskan dengan teori disonansi kognitif (cognitive dissonance theory) yang dikembangkan oleh Festinger (1957). Disonansi Kognitif mempunyai arti keadaan psikologis yang tidak menyenangkan yang timbul ketika dalam diri manusia terjadi konflik antara dua kognisi atau konflik antara perilaku dan sikap (Noviyanti, 2008: 106).

Trust and suspicion (kepercayaan dan kecurigaan) dalam model skeptisisme profesional yang diajukan Kee dan Knox (1970) menjelaskan keseimbangan antara kepercayaan auditor-klien dengan kecurigaan atas pengukuran yang tepat sebagaimana dikembangkan Shaub dan Lawrence (1996). Auditor yang memiliki tingkat kepercayaan yang tinggi terhadap auditi cenderung menurunkan skeptisisme profesional, sebaliknya kecurigaan yang tinggi atas pengukuran bukti audit cenderung membuat auditor bersikap skeptis dan tidak profesional. Dengan diimplementasikan skeptisisme profesional dalam pelaksanaan audit maka berimplikasi pada laporan hasil audit yang memuat temuan dan 
simpulan secara obyektif, serta rekomendasi yang konstruktif.

Penelitian ini juga dapat dijelaskan melalui the theory of planned of behavior (teori perilaku yang direncanakan) (Ajzen, 1991). Teori ini digunakan untuk memprediksi perilaku seseorang yang tidak sepenuhnya dibawah kendali individu. The theory of planned behavior menyatakan bahwa terdapat tiga determinan konseptual dari suatu intensi (Ajzen, 1991: 188) yaitu: attitude toward the behavior, subjective norm, dan perceived behavioral control. Pertama, sikap terhadap perilaku (attitude toward the behavior), mengacu pada sejauh mana seseorang memiliki evaluasi yang menguntungkan atau tidak menguntungkan atau penilaian dari perilaku yang bersangkutan, menjelaskan bagaimana sikap skeptisisme profesional dalam berbagai bentuk dan tingkatan yang dianggap memungkinkan bagi auditor. Kedua, faktor sosial disebut norma subjektif (subjective norm), merujuk pada tekanan sosial yang dirasakan untuk melakukan atau tidak melakukan perilaku. Lingkungan individu auditor dapat membentuk orientasi etika untuk membuat keputusan etis. Ketiga, pengendali perilaku yang dirasakan

\section{METODE PENELITIAN}

\section{Metode Analisis}

Pengujian data dalam penelitian ini meliputi: uji validitas, uji reliabilitas, transformasi data, uji normalitas, dan uji asumsi klasik. Persamaan struktural dalam analisis jalur yang digunakan untuk menguji hipotesis dengan tingkat signifikasi 0,05 , adalah sebagai berikut:

Persamaan substruktur 1:

$$
Y=\rho Y X_{1}+\rho Y X_{2}+\rho Y X_{3}+\varepsilon_{1}
$$

Persamaan substruktur 2 :

$$
\begin{aligned}
& Z=\rho Z X_{1}+\rho Z X_{2}+\rho Z X_{3}+\rho Z Y \\
& +\varepsilon_{2}
\end{aligned}
$$

(perceived behavioral control), mengacu pada persepsi kemudahan atau kesulitan melakukan perilaku dan diasumsikan untuk mencerminkan pengalaman masa lalu serta hambatan yang diantisipasi dan rintangan, mencerminkan persepsi auditor atas dasar pengalaman kerja dan kompetensi yang dimiliki.

Berdasarkan uraian pada pendahuluan dan kerangka pemikiran yang telah dikemukan di atas, maka hipotesis yang akan dikemukakan dalam penelitian adalah sebagai berikut: Hipotesis 1 : Orientasi etika, pengalaman, dan kompetensi berpengaruh positif terhadap Skeptisisme Profesional

Hipotesis 2 : Orientasi etika, pengalaman, kompetensi, dan skeptisisme profesional berpengaruh positif terhadap kualitas hasil audit

Hipotesis 3 : Orientasi etika, pengalaman, dan kompetensi berpengaruh positif terhadap kualitas hasil audit melalui skeptisisme profesional.

dalam hal ini:

$X_{1}=$ Variabel bebas (Orientasi etika)

$X_{2}=$ Variabel bebas (Pengalaman)

$X_{3}=$ Variabel bebas (Kompetensi)

$Y=$ Variabel terikat (Skeptisisme profesional)

$Z$ = Variabel terikat (Kualitas hasil audit)

$\rho=$ Parameter Koefisien Regresi / Koefisien Beta

$\varepsilon=\quad$ Standard Error 


\section{Populasi dan Sampel}

Populasi dalam penelitian ini adalah seluruh Pejabat Fungsional Auditor yang ditugaskan sebagai

\section{Definisi dan Operasionalisasi Variabel}

1) Orientasi Etika $\left(X_{1}\right)$

Orientasi etika merupakan kecondongan etika seseorang yang mempengaruhi pengambilan keputusan dalam menghadapi dilema etika. Orientasi etika diukur melalui karakteristik idealisme dan relativisme individu menggunakan The Ethics Position Questionnaire $(E P Q)$ sebagaimana diajukan Forsyth (1980).

2) Pengalaman $\left(X_{2}\right)$

Pengalaman dalam bekerja menunjukkan pekerjaan yang pernah dilakukan seseorang serta memberikan peluang di masa mendatang untuk menyelesaikan pekerjaan dengan lebih baik dan mengurangi risiko kesalahan. Pengalaman dapat dilihat dari lama bekerja dalam tahun sebagai auditor (years an auditor) (Herda dan Martin, 2016; Ye dkk, 2014) dan level dari pengalaman (experience level) dalam bentuk intensitas dan variasi penugasan audit yang diadopsi dari Libby dan Frederick (1990) dan Arens dkk (2014: 29).

3) Kompetensi $\left(X_{3}\right)$

Kompetensi merupakan kepribadian yang mendalam dan melekat pada setiap orang pada berbagai macam tugas dalam pekerjaannya yang diukur dari 3 dimensi yaitu pengetahuan (knowledge), keahlian (skill), dan anggota tim sebanyak 143 orang menggunakan Cluster Random Sampling yang dibagi kedalam 27 tim.

sikap (attitude) (Agoes, 2012; BPKP, 2010; Soesilo, 2003).

4) Skeptisisme profesional $(Y)$

Skeptisisme profesional adalah sikap yang mencakup pikiran yang selalu mempertanyakan dan melakukan pengujian secara kritis bukti (AAIPI, 2013: 18; ISA 200, para 13.1). Pengukuran terhadap skeptisisme profesional auditor mengadopsi penelitian yang dilakukan Hurtt (2010) dalam membangun karakteristik skeptisisme profesional yang meliputi: Questioning mind, The suspension of judgement, Search for knowledge, Interpersonal understanding, Autonomy, Self esteem.

5) Kualitas hasil audit $(Z)$

Kualitas audit internal jika dilihat dari sisi output, maka terkait dengan penyajian temuan dan rekomendasi audit yang terangkum dalam laporan hasil audit sebagaimana konsep output yang diajukan IAASB (2011) dan Kneckel dkk (2013). Kualitas hasil audit menggunakan indikator kualitas laporan audit internal yang digunakan Moeller (2009), yaitu: objectives, timing, and scope of the review, description of findings, suggestions for corrections, dan documentation of plans and clarification of views of auditee. 
HASIL PENELITIAN DAN PEMBAHASAN

Pengaruh orientasi etika, pengalaman, dan kompetensi terhadap Skeptisisme Profesional

Hasil pengujian hipotesis 1 dapat dilihat pada nilai koefisien dan

signifikasi pada persamaan substruktur

Tabel 2

Hasil Uji Hipotesis Parsial Persamaan Substruktur 1 ( $t$ Test)

\begin{tabular}{lccc}
\hline Variabel Independen & Std Coeff. (Beta) & $\mathbf{T}$ & Sig. \\
\hline Orientasi Etika $\left(\mathrm{X}_{1}\right)$ & 0.092 & 1.167 & 0.246 \\
\hline Pengalaman $\left(\mathrm{X}_{2}\right)$ & 0.042 & 0.567 & 0.572 \\
\hline Kompetensi $\left(\mathrm{X}_{3}\right)$ & 0.638 & 8.113 & 0.000 \\
\hline
\end{tabular}

Pengujian hipotesis dilakukan dengan uji signifikansi: alpha $=0,05$. Jika probabilitas $>0,05$, maka $\mathrm{H}_{0}$ diterima dan jika probabilitas $<0,05$, maka $\mathrm{H}_{0}$ ditolak. Dalam pengujian hipotesis parsial jika $t_{\text {hitung }}$ lebih kecil dari $\mathrm{t}_{\text {tabel }}$ maka $\mathrm{H}_{0}$ diterima dan Jika $\mathrm{t}_{\text {hitung }}$ lebih besar dari $\mathrm{t}_{\text {tabel }}$ maka $\mathrm{H}_{0}$ ditolak. Untuk taraf kesalahan 0,05 $(5 \%)$, df $1=\mathrm{n}-\mathrm{k}=99$, maka besarnya skor $t_{\text {tabel }}$ adalah 1,984. Sedangkan dalam pengujian simultan jika $F_{\text {hitung }}$ lebih kecil dari $\mathrm{F}_{\text {tabel }}$ maka $\mathrm{H}_{0}$ diterima dan Jika $\mathrm{F}_{\text {hitung }}$ lebih besar dari $\mathrm{F}_{\text {tabel }} \mathrm{H}_{0}$ ditolak. Dengan tingkat signifikansi sebesar $5 \%$ dan df1 $=3$ dan df $2=99$, didapat nilai $\mathrm{F}_{\text {tabel }}=2,696$

Dalam pengujian parsial sebagaimana dijelaskan pada tabel 2 di atas, dapat diketahui bahwa variabel orientasi etika $\left(X_{1}\right)$ diperoleh Skor $t_{\text {hitung }}$ $<\mathrm{t}_{\text {tabel }}$ yaitu 1,167 < 1,984 dan nilai Sig. $0,246>0,05$, variabel pengalaman $\left(\mathrm{X}_{2}\right)$ diperoleh Skor $\mathrm{t}_{\text {hitung }}<\mathrm{t}_{\text {tabel }}$ yaitu 0,567 $<$ 1,984 dan nilai Sig. 0,572 > 0,05, dan variabel kompetensi $\left(X_{3}\right)$ diperoleh Skor $\mathrm{t}_{\text {hitung }}>\mathrm{t}_{\text {tabel }}$ yaitu $8,113>1,984$ dan nilai Sig. $0,000<0,05$. Hasil ini membuktikan bahwa orientasi etika dan pengalaman tidak berpengaruh positif terhadap skeptisisme profesional, sedangkan kompetensi berpengaruh positif terhadap skeptisisme profesional.

Hasil penelitian ini menunjukkan bahwa dalam implementasi audit, kendati auditor mampu bersikap idealis, namun cenderung belum menerima sepenuhnya aturan atau prinsip moral yang bersifat universal, sehingga orientasi etika belum dapat meningkatkan sikap skeptisisme profesional. Kompleksitas tugas audit belum maksimal melalui intensitas berbagai jenis dan bidang audit, sehingga pengalaman belum dapat meningkatkan sikap skeptisisme profesional. Lebih lanjut, Auditor yang memiliki kompetensi, akan memahami berbagai teknik audit untuk mengembangkan keseimbangan trust and suspicion yang dimiliki, sehingga kompetensi yang dimiliki auditor dapat meningkatkan sikap skeptisisme profesional. 


\section{Hasil uji kecocokan model (goodness of fit)}

Tabel 3

Uji Hipotesis Simultan Persamaan Substruktur 1 (F Test)

\begin{tabular}{lccccc}
\hline Variabel Independen & F & Sig. & $\mathbf{R}^{2}$ & $\begin{array}{c}\text { Std. Error } \\
\text { of the Est. }\end{array}$ & $\begin{array}{c}\text { Std. } \\
\text { Deviation }\end{array}$ \\
\hline $\mathrm{X}_{1} \mathrm{X}_{2} \mathrm{X}_{3}$ & 27.014 & 0.000 & $46 \%$ & 3.966 & 5.269 \\
\hline
\end{tabular}

Dalam pengujian simultan sebagaimana dijelaskan pada tabel 3 di atas, dapat diketahui bahwa skor $\mathrm{F}_{\text {hitung }}$ $>$ nilai $\mathrm{F}_{\text {tabel }}$ yaitu 27,014 > 2,696 dan nilai Sig. $0,000<0,05$. Hasil ini membuktikan bahwa secara bersama (simultan), orientasi etika, pengalaman, dan kompetensi berpengaruh positif terhadap terhadap skeptisisme profesional. Dengan kompetensi yang dimiliki, maka auditor tidak hanya mengacu pada prosedur dan teknik yang relevan, namun juga pada implementasi audit sebelumnya serta pertimbangan etis dalam memutuskan, sehingga mampu meningkatkan sikap skeptisisme profesional. Std. Error of the Estimate adalah ukuran kesalah prediksi (Piyatno, 2012: 84), artinya kesalahan yang terjadi dalam memprediksi $Y$ sebesar 3,966, sedangkan standar deviasi $Y$ sebesar 5,269. Karena nilai Std. Error of the Estimate lebih kecil dari standar deviasi $Y$, maka model regresi lebih bagus dalam bertindak sebagai predictor $\mathrm{Y}$ daripada rata-rata $\mathrm{Y}$ itu sendiri (Santoso, 2014: 349), sehingga model persamaan struktural 1 sudah benar.

Persamaan Substruktur 1 berdasarkan hasil pengujian hipotesis 1 dapat dirumuskan sebagai berikut: $Y=0,092 x_{1}+0,042 x_{2}+0,638 x_{3}+0,55 \varepsilon_{1}$

\section{Pengaruh orientasi etika, pengalaman, dan kompetensi terhadap Skeptisisme Profesional}

Hasil pengujian hipotesis 2 signifikasi pada persamaan substruktur dapat dilihat pada nilai koefisien dan

Tabel 4

Hasil Uji Hipotesis Parsial Persamaan Substruktur 2 ( $t$ Test)

\begin{tabular}{lccc}
\hline Variabel Independen & $\begin{array}{c}\text { Std Coeff. } \\
\text { (Beta) }\end{array}$ & t & Sig. \\
\hline Orientasi Etika $\left(\mathrm{X}_{1}\right)$ & 0.032 & 0.326 & 0.745 \\
\hline Pengalaman $\left(\mathrm{X}_{2}\right)$ & 0.080 & 0.854 & 0.395 \\
\hline Kompetensi $\left(\mathrm{X}_{3}\right)$ & 0.134 & 1.064 & 0.290 \\
\hline S. Profesional $(\mathrm{Y})$ & 0.274 & 2.188 & 0.031 \\
\hline
\end{tabular}

Pengujian hipotesis dilakukan dengan uji signifikansi: alpha $=0,05$. Jika probabilitas $>0,05$, maka $\mathrm{H}_{0}$ diterima dan jika probabilitas $<0,05$, maka $\mathrm{H}_{0}$ ditolak. Dalam pengujian hipotesis parsial jika $t_{\text {hitung }}$ lebih kecil dari $\mathrm{t}_{\text {tabel }}$ maka $\mathrm{H}_{0}$ diterima dan Jika $\mathrm{t}_{\text {hitung }}$ lebih besar dari $\mathrm{t}_{\text {tabel }}$ maka $\mathrm{H}_{0}$ ditolak. Untuk taraf kesalahan 0,05 $(5 \%)$, df1 $=\mathrm{n}-\mathrm{k}=98$, maka besarnya skor $\mathrm{t}_{\text {tabel }}$ adalah 1,984. Sedangkan dalam pengujian simultan jika $F_{\text {hitung }}$ lebih kecil dari $\mathrm{F}_{\text {tabel }}$ maka $\mathrm{H}_{0}$ diterima dan Jika $\mathrm{F}_{\text {hitung }}$ lebih besar dari $\mathrm{F}_{\text {tabel }} \mathrm{H}_{0}$ 
ditolak. Dengan tingkat signifikansi sebesar 5\% dan df1 $=4$ dan df $2=98$, didapat nilai $\mathrm{F}_{\text {tabel }}=2,465$.

Dalam pengujian parsial sebagaimana dijelaskan pada tabel 4 di atas, dapat diketahui bahwa variabel orientasi etika $\left(X_{1}\right)$ diperoleh Skor thitung $<\mathrm{t}_{\text {tabel }}$ yaitu $0,326<1,984$ dan nilai Sig. $0,745>0,05$, variabel pengalaman $\left(\mathrm{X}_{2}\right)$ diperoleh Skor $\mathrm{t}_{\text {hitung }}<\mathrm{t}_{\text {tabel }}$ yaitu 0,854 $<$ 1,984 dan nilai Sig. 0,395 > 0,05, variabel kompetensi $\left(\mathrm{X}_{3}\right)$ diperoleh Skor $\mathrm{t}_{\text {hitung }}>\mathrm{t}_{\text {tabel }}$ yaitu $1,064<1,984$ dan nilai Sig. 0,290>0,05, dan variabel skeptisisme profesional (Y) diperoleh Skor $\mathrm{t}_{\text {hitung }}>\mathrm{t}_{\text {tabel }}$ yaitu $2,188>1,984$ dan nilai Sig. 0,031 < 0,05. Hasil ini membuktikan bahwa orientasi etika, pengalaman, dan kompetensi tidak berpengaruh positif terhadap kualitas hasil audit, sedangkan skeptisisme profesional berpengaruh positif terhadap kualitas hasil audit.

Hasil penelitian ini menunjukkan bahwa kendati auditor concern pada kesejahteraan orang lain, namun analisis individual belum dapat dikurangi sepenuhnya dibandingkan dengan ketaatan aturan atau prinsip moral yang bersifat universal, sehingga orientasi etika belum dapat meningkatkan kualitas hasil audit. Berbagai jenis penugasan dan bidang audit yang dialami auditor belum maksimal, sehingga pengalaman belum dapat meningkatkan kualitas hasil audit. Lebih lanjut, meskipun kompetensi auditor sudah memadai, namun tidak dapat meningkatkan kualitas hasil audit, hal ini membuktikan bahwa auditor yang berkompeten dalam implementasi audit secara formal belum mampu memberikan temuan dan rekomendasi yang substansial. Sedangkan sikap kritis terhadap bukti audit dengan keseimbangan trust and suspicion berimplikasi pada hasil audit yang semakin berkualitas, sehingga skeptisisme profesional dapat meningkatkan kualitas hasil audit.

\section{Hasil uji kecocokan model (goodness of fit)}

Tabel 5

Uji Hipotesis Simultan Persamaan Substruktur 2 (F Test)

\begin{tabular}{lccccc}
\hline Variabel Independen & F & Sig. & $\mathbf{R}^{2}$ & $\begin{array}{c}\text { Std. Error } \\
\text { of the Est. }\end{array}$ & $\begin{array}{c}\text { Std. } \\
\text { Deviation }\end{array}$ \\
\hline $\mathrm{X}_{1} \mathrm{X}_{2} \mathrm{X}_{3} \mathrm{Y}$ & 4.511 & 0.002 & $16 \%$ & 3.315 & 3.536 \\
\hline
\end{tabular}

Dalam pengujian simultan sebagaimana dijelaskan pada tabel 5 di atas,, diperoleh skor $\mathrm{F}_{\text {hitung }}>$ nilai $\mathrm{F}_{\text {tabel }}$ yaitu 4,511 > 2,465 dan nilai Sig. 0,002 $<0,05$, sehingga $\mathrm{H}_{2}$ ditolak dan $\mathrm{Ha}_{2 \mathrm{e}}$ diterima, artinya bahwa orientasi etika $\left(X_{1}\right)$, pengalaman $\left(X_{2}\right)$, dan kompetensi $\left(X_{3}\right)$, dan skeptisisme profesional $(Y)$ berpengaruh positif signifikan secara simultan terhadap kualitas hasil audit (Z) pada Inspektorat Jenderal Kementerian Agama. sikap skeptisisme profesional dapat dikembangkan jika mengimplementasikan prosedur dan teknik audit yang relevan dengan kompetensi yang dimiliki serta mengacu pada pengalaman dan pertimbangan etis dalam memutuskan, sehingga mampu meningkatkan kualitas hasil audit. Std. Error of the Estimate dengan nilai 3,315 lebih kecil dari standar deviasi $\mathrm{Z}$ dengan nilai 3,536, maka model persamaan struktural 2 sudah benar.

Persamaan Substruktur 2 berdasarkan hasil pengujian hipotesis 2 dapat dirumuskan sebagai berikut:

$Z=0,032 x_{1}+0,080 x_{2}+0,134 x_{3}+$ $0,274 y+0,84 \varepsilon_{1}$ 
Pengaruh orientasi etika, pengalaman, dan kompetensi terhadap Kualitas Hasil Audit Melalui Skeptisisme Profesional

Hasil pengujian hipotesis 3 dapat dilihat pada nilai koefisien dan signifikasi pada hubungan tidak langsung sebagai berikut:

Tabel 6

Pengujian Pengaruh Variabel Intervening

\begin{tabular}{|c|c|c|c|}
\hline Pengujian & $\mathrm{X}_{1} \rightarrow \mathrm{Z}$ & $\mathbf{X}_{2} \rightarrow \mathbf{Z}$ & $\mathbf{X}_{3} \rightarrow \mathbf{Z}$ \\
\hline Pengaruh Langsung & $=0,032$ & $=0,080$ & $=0,134$ \\
\hline - Signifikasi & Sig. $0.745>0.05$ & Sig. $0.395>0.05$ & Sig. $0.031<0.05$ \\
\hline $\begin{array}{l}\text { Pengaruh Tidak } \\
\text { Langsung }\end{array}$ & $\begin{array}{l}=0,092 \times 0,274 \\
=0,025\end{array}$ & $\begin{array}{l}=0,042 \times 0,274 \\
=0,012\end{array}$ & $\begin{array}{l}=0,638 \times 0,274 \\
=0,175\end{array}$ \\
\hline Signifikasi & $\begin{array}{l}\text { - } X_{1} \rightarrow Y \text { : Sig. } 0.246>0.05 \\
\text { - } Y \rightarrow Z \text { : Sig. } 0.031<0.05\end{array}$ & $\begin{array}{l}\text { - } \mathrm{X}_{2} \rightarrow \mathrm{Y} \text { : Sig. } 0.572>0.05 \\
\text { - } \mathrm{Y} \rightarrow \mathrm{Z} \text { : Sig. } 0.031<0.05\end{array}$ & $\begin{array}{l}\text { - } X_{3} \rightarrow Y \text { : Sig. } 0.00<0.05 \\
\text { - } Y \rightarrow Z \text { : Sig. } 0.031<0.05\end{array}$ \\
\hline Pengaruh Total & $\begin{array}{l}=0,032+0,025 \\
=0,057\end{array}$ & $\begin{array}{l}=0,080+0,012 \\
=0,092\end{array}$ & $\begin{array}{l}=0,134+0.175 \\
=0,309\end{array}$ \\
\hline
\end{tabular}

Berdasarkan tabel 6 di atas, maka dapat diketahui sebagai berikut:

1. Nilai signifikasi $X_{1}$ terhadap $Y$ sebesar $0,246>0,05$, dan $Y$ terhadap $Z$ sebesar $0,031<0,05$, artinya variabel $X_{1}$ berpengaruh positif namun tidak signifikan terhadap $Z$ yang dimediasi oleh skeptisisme profesional $(Y)$. Pengaruh tidak langsung orientasi etika $\left(X_{1}\right)$ terhadap kualitas hasil audit $(Z)(0,025)$ lebih kecil dari pengaruh langsung $(0,032)$.

2. Nilai signifikasi $X_{2}$ terhadap $Y$ sebesar $0,572>0,05$, dan $Y$ terhadap $Z$ sebesar $0,031<0,05$, artinya variabel $X_{2}$ berpengaruh positif namun tidak signifikan terhadap $Z$ yang dimediasi oleh skeptisisme profesional $(Y)$. Pengaruh tidak langsung pengalaman $\left(X_{2}\right)$ terhadap kualitas hasil audit $(Z)(0,012)$ lebih kecil dari pengaruh langsung $(0,080)$.
3. Nilai signifikasi $X_{3}$ terhadap $Y$ sebesar $0,000<0,05$, dan $Y$ terhadap $Z$ sebesar $0,031<0,05$, artinya variabel $X_{3}$ berpengaruh positif dan signifikan terhadap $Z$ yang dimediasi oleh skeptisisme profesional $(Y)$. Pengaruh tidak langsung kompetensi $\left(X_{3}\right)$ terhadap kualitas hasil audit $(Z)(0,175)$ lebih besar dari pengaruh langsung $(0,134)$.

Hasil penelitian ini menunjukkan bahwa orientasi etika dan pengalaman tidak berpengaruh positif terhadap kualitas hasil audit melalui skeptisisme profesional, sedangkan kompetensi berpengaruh positif terhadap terhadap kualitas hasil audit melalui skeptisisme profesional.

Hasil penelitian ini menunjukkan bahwa kendati orientasi etika dalam kondisi ideal yakni absolutist, namun auditor dalam tindakannya tidak didasarkan sepenuhnya pada aturan atau prinsip moral yang bersifat universal 
serta analisis individual masih digunakan dalam pengambilan keputusan, sehingga tidak mampu meningkatkan sikap skeptisisme profesional yang berimplikasi pada hasil audit yang tidak lebih baik. Dengan intensitas variasi berbagai jenis dan bidang audit yang belum maksimal, maka portfolio dalam memilah sensitivitas bukti audit dan keterangan auditi yang dimiliki tidak mampu meningkatkan sikap skeptisisme profesional yang berimplikasi pada hasil audit yang tidak lebih baik.

Dengan kompetensi auditor yang memadai maka auditor dapat mengimplementasikan prosedur dan teknik audit yang relevan secara formal, sehingga mampu meningkatkan sikap skeptisisme profesional. Lebih lanjut, secara substansial, dengan skeptisisme profesional auditor mampu mendeteksi kecurangan yang tersembunyi atas bukti audit, sehingga kompetensi auditor yang didukung oleh sikap skeptisisme profesional mampu meningkatkan kualitas hasil audit baik secara formal maupun substansial.

\section{Persamaan Pada Model Struktural}

Berdasarkan hasil analisis pengujian hipotesis pada persamaan substruktur 1 dan persamaan

\section{substruktur 2, maka diagram jalur model struktural pada penelitian ini adalah sebagai berikut}

Gambar 1

Diagram Jalur Persamaan Struktural Hasil Penelitian

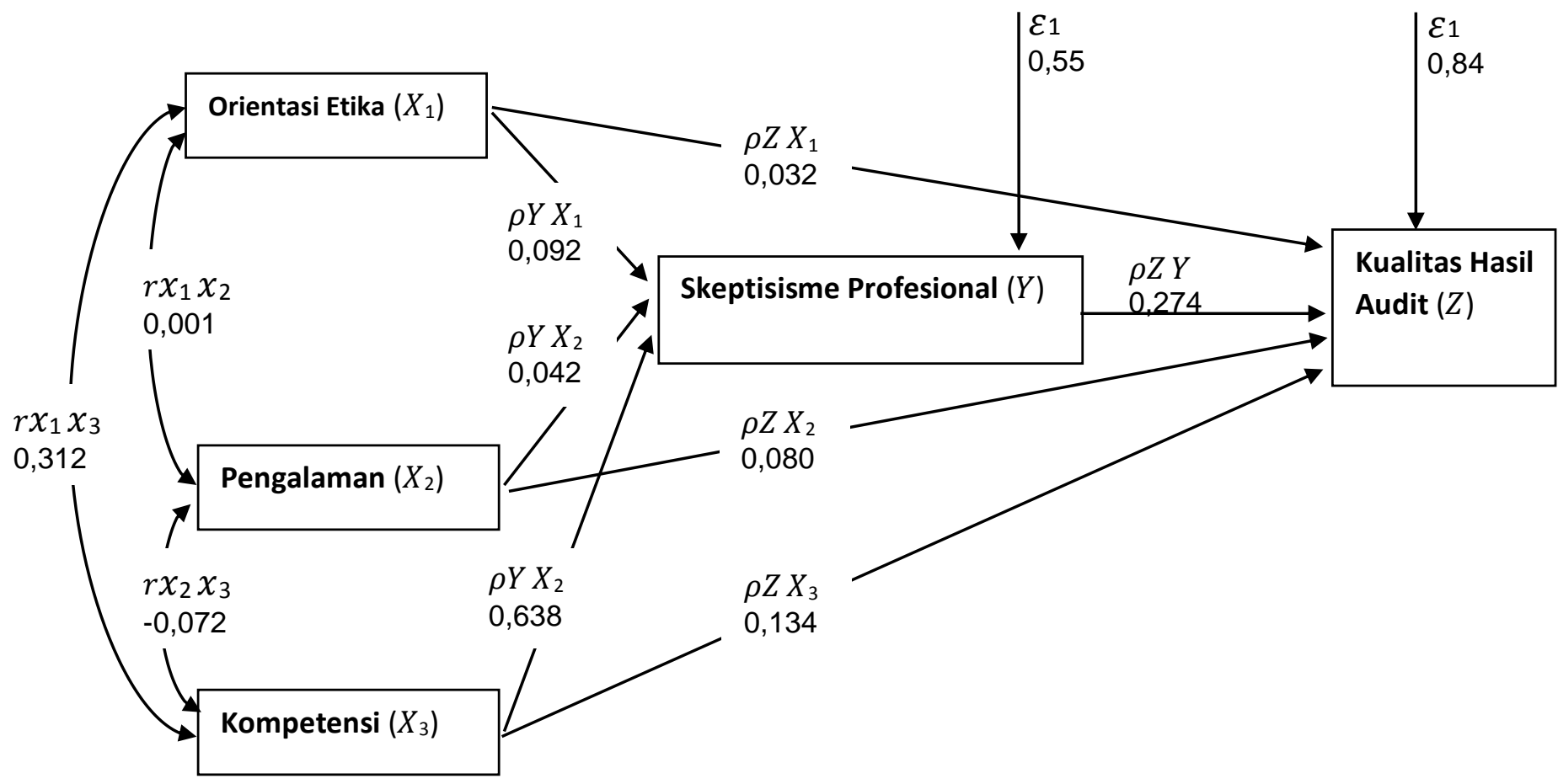

Persamaan struktural pada gambar 1 di atas adalah sebagai berikut:

Persamaan Substruktur $1 \quad: Y=0,092 x_{1}+0,042 x_{2}+0,638 x_{3}+0,55 \varepsilon_{1}$

Persamaan Substruktur $2 \quad: Z=0,032 x_{1}+0,080 x_{2}+0,134 x_{3}+0,274 y+0,84 \varepsilon$ 


\section{SIMPULAN DAN SARAN}

Berdasarkan hasil analisis, diperoleh kesimpulan bahwa:

1. Orientasi etika dan pengalaman tidak berpengaruh positif terhadap skeptisisme profesional, kompetensi berpengaruh positif terhadap skeptisisme profesional.

2. Orientasi etika, pengalaman, dan kompetensi tidak berpengaruh positif terhadap kualitas hasil audit, skeptisisme profesional berpengaruh positif terhadap kualitas hasil audit.

3. Orientasi etika dan pengalaman tidak berpengaruh positif terhadap kualitas hasil audit melalui skeptisisme profesional, sedangkan kompetensi berpengaruh positif terhadap terhadap kualitas hasil audit melalui skeptisisme profesional.

Kompetensi tidak berpengaruh positif secara langsung terhadap kualitas hasil audit, namun melalui skeptisisme profesional berpengaruh positif. Hasil ini menjelaskan bahwa dengan kompetensi yang dimiliki, auditor dapat dengan baik menemukan kekeliruan dalam implementasi audit sehingga mampu memberikan hasil audit yang baik secara formal. Lebih lanjut, kecurangan yang disembunyikan oleh auditi dapat dideteksi apabila auditor senantiasa mengembangkan sikap skeptisisme profesionalnya, maka mampu memberikan hasil audit secara substansial yaitu temuan dan rekomendasi yang berguna, sehingga kompetensi auditor yang didukung oleh sikap skeptisisme profesional mampu meningkatkan kualitas hasil audit baik secara formal maupun substansial.

Saran yang diajukan berdasarkan hasil penelitian ini adalah:

1. Hasil penelitian ini membuktikan bahwa orientasi etika tidak berpengaruh positif baik terhadap skeptisisme profesional maupun terhadap kualitas hasil audit. Orientasi etika juga tidak berpengaruh positif terhadap kualitas hasil audit melalui skeptisisme profesional. Pimpinan organisasi menuntut hasil audit yang objektif dan auditi mengharapkan perlakuan yang adil. Oleh karena itu, agar dapat memberikan hasil nyata terhadap peningkatan skeptisisme profesional dan kualitas hasil audit, maka pengendalian mutu dan kode etik tidak hanya menjadi acuan kaidah normatif dari regulator, namun diimplementasikan dengan reward dan punishment melalui atasan langsung. Lebih lanjut, dari sisi auditi, pimpinan organisasi dapat memaksimalkan mekanisme pengaduan dan fungsi whistleblowing system yang dapat menjadi warning bagi auditor untuk dapat senantiasa bersikap etis, sehingga auditor dapat semakin fokus pada kepentingan publik dan tidak merugikan auditi yang tidak bersalah.

2. Hasil penelitian ini membuktikan bahwa pengalaman tidak berpengaruh positif baik terhadap skeptisisme profesional maupun terhadap kualitas hasil audit. Pengalaman juga tidak berpengaruh positif terhadap kualitas hasil audit melalui skeptisisme profesional. Dengan semakin banyaknya penugasan audit, diharapkan dapat menjadi auditor menjadi lebih skeptis atas bukti audit secara proporsional dan memberikan temuan dan rekomendasi hasil audit yang lebih baik. Oleh karena itu, agar dapat memberikan hasil nyata 
terhadap peningkatan skeptisisme profesional dan kualitas hasil audit, maka tidak hanya intensitas penugasan audit yang ditingkatkan, namun variasi berbagai jenis dan bidang audit juga ditingkatkan melalui perencanaan audit dari pengendali teknis, sehingga seorang auditor memiliki peluang mendapatkan jenis pekerjaan yang berbeda pada setiap penugasan.

3. Hasil penelitian ini membuktikan bahwa kompetensi berpengaruh positif terhadap skeptisisme profesional, namun tidak berpengaruh positif terhadap kualitas hasil audit. Sedangkan kompetensi auditor berpengaruh terhadap kualitas hasil audit melalui skeptisisme profesional. Dengan

\section{DAFTAR PUSTAKA}

Abbott, Lawrence K. Daugherty, Brian. Parker, Susan. Peters, Gary F. 2016. Internal Audit Quality and Financial Reporting Quality: The Joint Importance of Independence and Competence. Journal of Accounting Research. Vol. 54 No. 1 March 2016.

Agoes, Sukrisno. 2012. Auditing: Petunjuk Praktis Pemeriksaan Akuntan Oleh Akuntan Publik (Jilid I). Edisi keempat. Salemba Empat, Jakarta.

Ajzen, Icek. 1991. The Theory of Planned Behavior. Organizational Behavior And Human Decision Processes 50. p. 179-211.

Arens, Alvin A. Elder, Randal J. Beasley, Mark S. 2014. Auditing and Assurance Service: An Integrated Approach (Fifteenth edition). kompetensi yang memadai diharapkan memberikan hasil audit yang lebih baik, namun auditor yang berkompeten saja tidak cukup, harus senantiasa mengembangkan sikap skeptisisme profesional. Oleh karena itu, agar memberikan hasil nyata terhadap peningkatan kualitas hasil audit, maka auditor dengan kompetensi yang memadai dapat ditingkatkan sikap skeptisisme profesionalnya melalui keikutsertaan pendidikan dan pelatihan (diklat) teknis substansi analisis pemecahan masalah, audit berbasis risiko, dan audit investigatif, serta penugasan audit dengan tingkat risiko yang tinggi, seperti: audit investigatif, audit pada unit eselon I, dan audit pada program-program prioritas.

Pearson Education, New Jersey.

Arena, Marika. Azzone, Giovanni. 2009. Internal Audit Effectiveness: Relevant Drivers Of Auditees Satisfaction. International Journal of Auditing. Vol. 13, No. 1, pp 43-60.

Bedard, Jean C. Johnstone, Karla M. Smith, Edward F. 2010. Audit Quality Indicators: A Status Update on Possible Public Disclosures and Insights from Audit Practice. Current Issues in Auditing. Volume 4, Issue 1 2010. Pages C12-C19.

Belay, Zeleke. 2007. A Study on Effective Implementation of Internal Audit Function to Promote Good Governance in the Public Sector. Ethiopian Civil Service College Research. Publication \& 
Consultancy Coordination Office.

Bing, Jueming (Jimmy). Huang, Chu Xin. Li, Anqi (Linda). Zhu, Xinyi (Lydia). 2014. Audit Quality Research Report. Australian National Centre for Audit and Assurance Research.

Chadegani, Arezoo Aghaei. 2011. Review Of Studies On Audit Quality. $2011 \quad$ International Conference on Humanities, Society and Culture. IPEDR Vol.20 (2011) (C) (2011) IACSIT Press, Singapore.

Dauber, Nick A., dkk., 2008, Complete Guide to Auditing Standards, and Other Professional Standards for Accountants, John Wiley \& Sons Inc, Hoboken.

DeFond, Mark. Zhang, Jieying. 2014. A Review Of Archival Auditing Research. Journal of Accounting and Economics 58 (2014) 275-326.

Enofe, A. O. Mgbame, C. J. OsaErhabor,V. E. Ehiorobo, A. J. 2013. The Role of Internal Audit in Effective Management in Public Sector. Research Journal of Finance and Accounting. ISSN 2222-1697 (Paper) ISSN 2222-2847 (Online). Vol.4, No.6, 2013.

Festinger, Leon. 1957. A Theory of Cognitive Dissonance. Stanford University Press. Calfornia.

Forsyth, Donelson R. 1980. A Taxonomy of Ethical Ideologies. Journal of Personality and Social Psychology. Journal of Personality and Social Psychology. Vol. 39, No. 1, 175-184.
Forsyth, Donelson R. Nye, Judith L. Kelley, Karl. 1988. Idealism, Relativism, And The Ethic of Caring. The Journal of Psychology, 122 (3), p. 243248. Taylor \& Francis Group.

Francis, Jere R. 2011. A Framework for Understanding and Researching Audit Quality. Auditing: A Journal of Practice \& Theory. Vol. 30, No. 2, May 2011. pp. 125-152.

Herda, David N. Martin, Kasey A. 2016. The Effects of Auditor Experience and Professional Commitment on Acceptance of Underreporting Time: A Moderated Mediation Analysis. Current Issues in Auditing InPress.

Hurtt, R. Kathy. 2010. Development of a Scale to Measure Professional Skepticism. Auditing: A Journal of Practice $\&$ Theory, Vol. 29, No. 1, May 2010, pp. 149-171. American Accounting Association.

International Auditing and Assurance Standards Board (IAASB). 2011. Audit Quality: An IAASB Perspective. New York.

Januarti, Indira. Faisal. 2010. Pengaruh Moral Reasoning Dan Skeptisisme Profesional Auditor Pemerintah Terhadap Kualitas Audit Laporan Keuangan Pemerintah Daerah. Jurnal Simposium Nasional Akuntansi 13.

Kee, H. W. Knox, R. E. 1970. "Conceptual and Methodological Consideration in the Study of Trust and Suspicion." The Journal of Conflict Resolution. Vol.14, No.3.

Knechel, W. Robert. Krishnan, Gopal V. Pevzner, Mikhail. Shefchik, 
Lori B. Velury, Uma K. 2013. Audit Quality: Insights from Academic Literature. Auditing: A Journal of Practice \& Theory. Vol. 32, Supplement 1 2013, pp. 385-421.

Libby, Robert. Frederick, David M. 1990. Experience and the Ability to Explain Audit Findings. Journal of Accounting Research. Vol. 28, No. 2 (Autumn, 1990), pp. 348-367.

Martin, Roger D. 2013. Audit Quality Indicators: Audit Practice Meets Audit Research. Current Issues in Auditing. Volume 7, Issue 2, 2013. Pages A17-A23.

Mihret, Dessalegn Getie. Yismaw, Aderajew Wondim. 2007. Internal Audit Effectiveness: An Ethiopian Public Sector Case Study. Managerial Auditing Journal, 22 (5). pp. 470-484. ISSN 0268-6902.

Moeller, Robert R. 2009. Brink's Modern Internal Auditing: A Common Body Of Knowledge (7th Ed). John Wiley \& Sons, Inc., Hoboken, New Jersey.

Noe, Raymond A. 2010. Employee training and development (5th ed). McGraw-Hill/Irwin, a business unit of The McGrawHill Companies, Inc. New York.

Noviyanti, Suzy. 2008. Skeptisisme Profesional Dalam Mendeteksi Kecurangan. Jurnal Akuntansi dan Keuangan Indonesia, Juni 2008, Vol. 5, No. 1, hal. 102125

Sarwono, Jonathan. 2007. Analisis Jalur Untuk Riset Bisnis Dengan SPSS. CV. Andi Offset. Yogyakarta.

Sawyer, B. Lawrence. 1995. An Internal Auditor Philosophy. The
Internal Auditor. August, pp. 46-55.

Shaub, M.K. Lawrence, J. E. 1996. "Ethics, Experience and Profesional Scepticism: A Situational Analysis." Behavioral Research in Accounting. Vol.8.

Shermon, Ganesh, 2004, Competency Based HRM (A Strategic Resource For Competency Mapping, Assessment And Developing Centres), Tata McGraw-Hill, Delhi.

Soesilo, Willy. 2003. Audit Mutu Internal. PT. Vorqistatama Binamega.

Sugiyono. 2009. Metode Penelitian Bisnis (Pendekatan Kuantitatif, Kualitatif \& $R \& D)$. Cet. Ke13. CV. Alfabeta. Bandung.

Suraida, Ida. 2005. Pengaruh Etika, kompetensi, pengalaman dan risiko audit terhadap skeptisisme profesional auditor dan ketepatan pemberian opini akuntan publik dalam audit laporan keuangan perusahaan. Sosiohumaniora. Vol. 7, No. 3, November 2005 : h. 186 - 202.

Sukriah, Ika. Akram. Inapty, Biana Adha. 2009. Pengaruh Pengalaman Kerja, Independensi, Obyektifitas, Integritas dan Kompetensi Terhadap Kualitas Hasil Pemeriksaan. Jurnal Simposium Nasional Akuntansi 12.

Sabrina K., Rr. Januarti, Indira. 2012. Pengaruh Pengalaman, Keahlian, Situasi Audit, Etika Dan Gender Terhadap Ketepatan Pemberian Opini Auditor Melalui Skeptisisme Profesional Auditor (Studi Kasus Pada KAP Big Four di Jakarta). Simposium Nasional 
Akuntansi 15 Banjarmasin. Universitas Lambung Mangkurat, 20-23 Sept 2012.

Tjokroamidjojo, Bintoro. 2000. Reformasi Birokrasi Ke Arah Good Governance, Bisnis dan Birokrasi (Jurnal Ilmu Administrasi dan Organisasi), No. I/Vol. I/Juli/2000.

Qi, Xi'an Baolei. Li, Xi'an Bin. Tian, Xi'an Gaoliang. 2015. What Do We Know About The Variance Of Audit Quality? An Empirical Study From The Perspective of Individual Auditor. The Journal of Applied Business Research. January/February 2015 Volume 31, Number 1.

Queena, Precilia Prima. Rohman, Abdul. 2012. Analisis FaktorFaktor Yang Mempengaruhi Kualitas Audit Aparat Inspektorat Kota/Kabupaten Di Jawa Tengah. Diponegoro Journal Of Accounting,

\section{Peraturan}

Asosiasi Auditor Intern Pemerintah Indonesia (AAIPI). 2013. Standar Audit Intern Pemerintah Indonesia. Jakarta. Government Internal Audit Profession HM Treasury, 2007, Government Internal Audit Competency Framework.

International Federation of Accountants (IFAC). 2009. International Standard On Auditing 200: Overall Objectives of The Independent Auditor And The Conduct of An Audit In Accordance With International Standards On Auditing.
Volume 1, Nomor 2, Tahun 2012, Halaman 1-12.

Wooten, Thomas C. 2003. Research About Audit Quality. The CPA Journal. January 2003; 73, pg. 48.

Ye, Kangtao. Yuan, Rongli. Cheng, Yingli. 2014. Auditor Experiences, Accounting Firm Size, and Client Ownership. Frontiers of Business Research in China, Volume 8, Issue 2, pages $206-226$.

Zarkasyi, Srihadi W. 2009. Pentingnya Ethical Orientation Bagi Akuntan Publik: Suatu Studi Deskriptif. Working Paper In Accounting and Finance, October 2009. Center For Accounting Development, Department of Accounting, Padjadjaran University.

Ziegenfuss, Douglas E. 2000. Measuring Performance. The Internal Auditor. February 2000; 57. pg. 36.

(Effective for audits of financial statements for periods beginning on or after December 15, 2009.

Peraturan Menteri Negara Pendayagunaan Aparatur Negara (Permenpan) Nomor: PER/05/M.PAN/03/2008

Tentang Standar Audit Aparat Pengawasan Intern Pemerintah.

Peraturan Kepala Badan Pengawasan Keuangan dan Pembangunan (Perka-BPKP) Nomor: PER211/K/JF/2010 Tentang Standar Kompetensi Auditor. 